\title{
STRATEGI PENGEMBANGAN PENDIDIKAN MULTIKULTUTRAL DI INDONESIA
}

\author{
Apri Wahyudi \\ STIT Pringsewu Lampung \\ Wonodadi, Gading Rejo, Pringsewu Regency, Lampung 35372 \\ apri.1688@yahoo.com
}

\section{Elhefni}

UIN Raden Fatah Palembang

Jalan Prof.K.H.Zainal Abidin Fikri KM.3,5, Lawang Kidul, Ilir Timur II, Pablawan, Kemuning, Kota Palembang,

Sumatera Selatan 30111

abifarban1973@gmail.com

\begin{abstract}
Multicultural education needs to be nurtured both in formal and non-formal education because of Indonesia's cultural potential, tradition, and geographical environment, and demographics is remarkable. Education has a major role to play in promoting multicultural understanding. The cultivation of such understanding should be carried out as early as possible, so that it will continue to be constructed in the cognition of the child's sense of ownership and pride of the nation's culture until he grows up so that a democratic and egalitarian attitude will emerge to accept cultural diversity. To achieve that, the strategy of multicultural education development is needed. Multicultural education development strategies that can be undertaken, ie curriculum development, professional quality improvement of educational staff, development of education management systems, development of higher education system, equality of community perception, inculcation of recognition and appreciation of diversity (culture or culture, ethnicity, race, Religion, worldview and so on), avoiding views that assume that one group is superior to the other, and fosters and accustoms to a dialogical attitude.
\end{abstract}

Keyword: development strategy, multicultural education

\begin{abstract}
Abstrak
Pendidikan multikultural perlu ditumbubkembangkan baik di pendidikan formal maupun nonformal karena potensi yang dimiliki Indonesia secara kultural, tradisi, dan lingkungan geografi, serta demografis sangat luar biasa. Pendidikan mempunyai peran besar untuk memberikan penanaman pemahaman multikultural. Penanaman pemahaman tersebut sebaiknya dilaksanakan sedini mungkin, sehingga terus akan terkonstruksi dalam kognisi anak rasa kepemilikan dan kebanggaan akan budaya bangsa hingga ia dewasa nanti sehingga nanti muncul suatu sikap demokratis dan egaliter untuk bisa menerima keragaman budaya. Untuk mencapai itu maka diperlukan strategi pengembangan pendidikan multikultura. Strategi pengembangan pendidikan multikultural yang dapat dilakukan, yaitu pengembangan kurikulum, peningkatan kualitas profesional tenaga kependidikan, pengembangan sistem pengelolaan pendidikan, pengembangan sistem pendidikan tinggi, penyamaan persepsi masyarakat, menanamkan pengenalan (pemahaman) dan penghargaan terhadap ke-
\end{abstract}


beragaman (kultur atau budaya, etnis, ras, agama, pandangan bidup dan seterusnya), menghindari pandangan-pandangan yang menganggap babwa kelompok yang satu lebib unggul dari kelompok yang lain, dan menumbubkan dan membiasakan sikap dialogis.

Keyword: strategi pengembangan, pendidikan multikultural

\section{Pendahuluan}

Pendidikan merupakan media yang tepat untuk mengenalkan multikultural. Inti dari keberhasilan multikultural adalah keinginan untuk menerima budaya kelompok lain, etnik, gender, bahasa dan keberanekaan agama sebagai suatu bentuk keseimbangan dan membentuk satu kesatuan. Pendidikan multicultural harus didekati dengan strategi pembelajaran dan kurikulum yang mengarahkan kepada proses pembelajarannya.

Berdasarkan UU Sisdiknas No. 20 Tahun 2003, pendidikan nasional adalah pendidikan yang berdasarkan Pancasila dan UUD Dasar Negara RI 1945 yang berakar pada nilai-nilai agama, kebudayaan nasional Indonesia, dan tanggap terhadap tuntutan perubahan zaman. Di dunia, Indonesia merupakan salah satu negara majemuk dengan multikultural terbesar. Atho' Mudzhar berpendapat bahwa multikulturalitas bangsa Indonesia ini dapat dibagi menjadi dua, yaitu vertikal dan horizontal. Dalam vertikal dimaknai dengan realitas tentang adanya pelapisan sosial atas-bawah dalam susunan kemasyarakan sebagai akibat signifikansi masing-masing individu baik di bidang politik, sosial, ekonomi, maupun pendidikan. Sedangkan dalam horizontal dimaknai berdasarkan kesatuan sosial budaya suku, adat-istiadat, agama, ras, dan bahasa.

Di Indonesia, penyadaran dan paham multikultural sangat penting untuk dilakukan mengingat arus globalisasi informasi dan mobilitas penduduk yang konflik yang mampu menghancurkan sendi-sendi kehidupan berbangsa dan bernegara. Perbedaan-perbedaan yang ada di Negara Indonesia akan menjadi beban atau kekayaan tergantung bagaimana cara mengolahnya. Bhineka Tunggal Ika adalah semboyan yang telah dicetuskan oleh para founding fathers bangsa ini, yang diharapkan masyarakat Indonesia mampu hidup saling berdampingan dalam suasana aman, nyaman, damai, tentram, dan sejahtera.

\section{Pembahasan}

\section{Kerangka Konsep Strategi Pengembangan Pendidikan Multikultural di Indonesia}

Istilah strategi pada mulanya digunakan dalam dunia militer dan diartikan sebagai suatu cara penggunaan seluruh kekuatan militer untuk memenangkan suatu peperangan. Dalam menyusun strategi perlu memperhitungkan berbagai faktor, baik dari dalam maupun dari luar. Dalam dunia pendidikan, strategi diartikan sebagai a plan, method, or series of activities designed to achieve a particular educatioan goal. Jadi, strategi pembelajaran dapat diartikan sebagai perencanaan yang berisi tentang rangkaian kegiatan yang didesain untuk mencapai tujuan pendidikan tertentu. ${ }^{1}$

Multikultural mempunyai arti beraneka ragam kebudayaan. Akar katanya yaitu kebudayaan, yaitu kebudayaan yang dilihat dari fungsinya sebagai pedoman bagi kehidupan manusia. Istilah multikultural merujuk pada sosial antropologis adanya pluralitas kelompok etnis, bahasa, agama dan juga bisa mengasumsikan sebuah sikap demokratis dan egaliter untuk bisa menerima keragaman kebudyaan. ${ }^{2}$

Mahfud menyatakan, Pendidikan multikultural secara etimologi terdiri dari dua kata, yaitu pendidikan dan kultural. Pendidikan secara sederhana dan umum, bermakna sebagai usaha

${ }^{1}$ Junaedi, dkk., Strategi Pembelajaran, (Surabaya: LAPISPGMI, 2008), h. 1.8

${ }^{2}$ M. Sukaardjo dan Ukim Komarudin, Landasan Pendidikan; Konsep dan Aplikasinya, (Jakarta: Rajawali Pers, 2009), h. 70 
untuk menumbuhkan dan mengembangkan pontensi-potensi bawaan, baik jasmani maupun rohani, sesuai dengan nilai-nilai yang ada dalam masyarakat dan kebudayaan. Multikultural diartikan sebagai keragaman kebudayaan, aneka kesopanan. ${ }^{3}$

Pendidikan multikultural adalah pendidikan untuk people of color atau pendidikan yang hendak mengembangkan (mengekplorasi) perbedaan sebagai bentuk keniscayaan. ${ }^{4}$ Pendidikan Multikultural merupakan suatu rangkaian kepercayaan (set of beliefs) dan penjelasan yang mengakui dan menilai pentingnya keragaman budaya dan etnis dalam membentuk gaya hidup, pengalaman sosial, identitas pribadi, kesempatan pendidikan dari individu, kelompok, maupun negara. ${ }^{5}$

Pendidikan multikultural adalah ide, gerakan pembaharuan pendidikan dan proses pendidikan yang tujuan utamanya adalah untuk mengubah struktur lembaga pendidikan supaya siswa, baik pria maupun wanita, siswa berkebutuhan khusus, dan siswa yang merupakan anggota dari kelompok ras, etnis, dan kultur yang bermacam-macam itu akan memiliki kesempatann yang sama untuk mencapai prestasi akademis di sekolah. ${ }^{6}$

Pendidikan multikultural perlu ditumbuhkkembangkan karena potensi yang dimilki Indonesia seara kultural, tradisi, dan lingkungan geografi, serta demografis sangat luar biasa, baik pendidikan formal maupun non formal. Jalur pendidikan mempunyai peran besar untuk mengatasi hal ini. Pemahaman multikultural sebaiknya dilaksanakan sedini mungkin, sehingga terus akan terkonstruksi dalam kognisi anak rasa

${ }^{3}$ Suniti, Kurikulum Pendidikan Berbasis Multikultural, Jurnal Edueksos, Vol III No. 2, Juli-Desember 2104, h. 27, https://www. syekhnurjati.ac.id/jurnal/index.php/edueksos/article/view/354

${ }^{4}$ Akhyar Yusuf Lubis, Pemikiran Kritis Kontemporer dari Teori Kritis, Culture Studies, Feminisme, Postkolonial Hingga Multikulturalisme, (Jakarta: Rajawali Pers, 2015), h.190

${ }^{5}$ James A. Bank dan Cherry A. McGee(ed), Handbook of Research on Multicultural Education. (San Francisco: Jessey-Bass, 2001), h. 21

${ }^{6}$ Yaya Suryana dan Rusdiana, Pendidikan Multikultural Suatu Upaya Pengetahuan Jati Diri Bangsa Konsep-Prinsip-Implementasi, (Bandung: Pustaka Setia, 2015), h. 196 kepemilikan dan kebanggaan akan budaya bangsa hingga ia dewasa nanti. ${ }^{7}$

Jadi, berdasarkan pendapat di atas pendidikan multikultural merupakan pemahaman tentang beraneka ragam kebudayaan, ide, gerakan pembaharuan pendidikan dan proses pendidikan yang tujuan utamanya adalah untuk mengubah struktur lembaga pendidikan dan mengembangkan (mengekplorasi) perbedaan sebagai bentuk keniscayaan supaya siswa, baik pria maupun wanita, siswa berkebutuhan khusus, dan siswa yang merupakan anggota dari kelompok ras, etnis, dan kultur yang bermacam-macam itu akan memiliki kesempatann yang sama untuk mencapai prestasi akademis di sekolah. Pemahaman multikultural tersebut sebaiknya dilaksanakan sedini mungkin, sehingga terus akan terkonstruksi dalam kognisi anak rasa kepemilikan dan kebanggaan akan budaya bangsa hingga ia dewasa nanti.

\section{Inkorporasi Pendidikan Multikikultural ke dalam Program Pendidikan}

Program pendidikan anak dalam inkorporasi pendidikan multikultural memiliki harapan dan cita-cita sebagai

a. Pendidikan yang menghargai pluralisme budaya. Pluralisme budaya yang mencangkup torelansi, merangkul dan keragaman pengalaman manusia yang diharapkan memberikan kearifan.

b. Alternatif dari membiarkan anak memperoleh sendiri pengalaman pluralisme budaya-sporadis dan fragmentaris.

c. Pendidikan secara eksplisit mengakui dan menyambut keragaman dari warisan etnik yang ditemukan dalam diri setiap orang yang disebut "orang Indonesia".

d. Pendidikan yang tidak memaksa atau menolak anak karena identitas suku, agama, ras, dan golongan.

\footnotetext{
${ }^{7}$ M. Sukardjo dan Ukim Komarudin, Op. Cit., h. 70-71
} 
e. Pendidikan yang mengakui kebutuhan dan manfaat anak untuk berbagi bersama diversitas warisan etnik mereka.

f. Pendidikan yang mengakui pentingnya semua anak memilkik banyak kesempatan untuk berinteraksi secara positif dan personal dengan anak-anak dari berbagai latar belakang sosioekonomi dan warisan budaya.

g. Pendidikan yang memberikan kesempatan setiap siswa untuk membantu berkembangnya sense of self.

2. Menerjemahkan Konsep Pluralisme Budaya ke dalam Praktik Pendidikan Multikultural

Salah satu definisi ke-bhineaka-an budaya yang diadopsi dari the National Coalition of Cultur Pluralism adalah sebagai berikut:

Cultural pluralism refers to a state of equel coexistence in a mutually supportive relationship within the boundaries or framework of one nation of people of diverse cultures, with significantly different patterns of belief, behavior, color and in many cases with dirretent languages.

Pluralisme budaya memvisikan sebuah masyarakat multietnik yang sling menghormati dan mengapresiasi berbagai budaya, dan memiliki hak yang sama dalam kerangka pelestarian dan pengembangan tradisi budayanya masing-masing.

Program pembelajaran multikultural yang akan dikembangkan merupakan sebuah program pendidikan yang menyediakan lingkungan belajar ganda kepada siswa (multiple learning environments), yang memiliki kesesuaian dengan kebutuhan dasar akademis dan sosial siswa. Model pembelajaran multikultural dikembangkan dan diarahkan pada pencapaian kompetensi-kompetensi tentang

a. Nilai-nilai persatuan kesatuan, demokrasi, keadilan, kebebasan, persamaan derajat atau saling menghargai dalam keragaman budaya

${ }^{8}$ Yaya Suryana dan A. Rusdiana, Op. Cit, h. 226-7 b. Latar belakang budaya sendiri dan budaya lain dalam masyarakat sehingga menumbuhkan pemahaman dalam masyarakat.

c. Isu-isu dan masalah keseharian melalui sebuah proses demokratis atau inkuiri dialogis

d. Konseptualisasi dan aspirasi sebuah masyarakat yang lebih baik, demokrais, dan memiliki persamaan derajat. ${ }^{9}$

\section{Tema Pendidikan Multikultural di Indonesia}

\section{Tema Ketuhanan}

Tema ketuhanan dimaksudkan untuk membentuk sikap sadar terhadap nilai-nilai, normanorma religiusitas siswa, meyakini dan menjalankan ajaran agama sesuai dengan agama dan kepercayaan dalam berkehidupan pada masyarakat yang beragam. Tema ketuhanan mencakup aspek-aspek berikut

a. Ketakwaan, yaitu sikap dan perilaku siswa yang mencermikan ketaatan, ketundukan dan keyakinan terhadap Tuhan Yang Maha Esa.

b. Toleransi, yaitu sikap menenggang rasa (menghargai, membolehkan) orang lain untuk beragama, berkepercayaan, berpendirian, dan berpendapat berbeda dengan diri individu. Toleransi hanya mungkin terjadi apabila orang rela merelativisasi klaim-klaimnya. Toleransi jangan sampai terjebak pada ego-sentrisme. Ego-sentrisme di sini adalah sikap seorang mentoleransi yang lain demi diri sendiri. ${ }^{10}$

\section{Tema Kemanusiaan}

Tema kemanusiaan dapat membenuk sikap peduli dan menjunjung tinggi nilai-nilai kemanuaan, dengan mengakui persamaan derajat,

${ }^{9}$ Ibid., h. 228-9

${ }^{10}$ Samrin, Konsep Pendidikan Multikultural, Jurnal AlTa'dib, Vol. 7 No. 2 Juli-Desember 2014, h. 132, http://ejournal. iainkendari.ac.id/index.php/al-tadib/article/view/321 
persamaan hak, dan persamaan kewajiban sesame manusia. Tema kemanusiaan mencakup humanis dan kesederajatan.

\section{Tema Persatuan dan Kesatuan}

Tema persataun dan kesatuan dapat membentuk pikiran, pemahaman, dan sikap atau perilkau yang senatiasa mengutamakan keutuhan dan kedaulatan kolektif sebagai warga masyarakat dan warga bangsa dengan semangat pluralitas antarbudaya.

\section{Tema Kerakyatan}

Tema ini dimaksudkan untuk dapat membentuk sikap yang demokratis, terbuka terhadap keragaman, menghargai aspirasi antarsesama, serta menjunjung tinggi nilai-nilai kebenaran dalam mewujudkan masyarakat pluralis yang damai dan bermartabat.

\section{Tema Keadilan}

Tema keadilan dapat membentuk sikap empati terhadap orang lain serta memiliki kepekaan sosial terhadap sesame manusia, merasa sama dan sederajat dalam hubungan sosial serta anti terhadap diskriminasi atau marginalisasi. ${ }^{11}$ Adil yaitu wawasan yang "seimbang" dalam memandang, menilai atau menyikapi sesuatu atau seseorang. Sikap tersebut dilakukan hanya setelah mempertimbangkan segala segi tentang sesuatu atau seseorang tersebut secara jujur dan seimbang dengan penuh i'tikad baik dan bebas dari prasangka. ${ }^{12}$

\section{Tema Silaturrahmi}

Tema silaturrahmi merupakan tema pertalian rasa cinta kasih antara sesama manusia. Sifat utama Tuhan adalah kasih sebagai satu-satunya sifat Ilahi yang diwajibkan sendiri atas diri-Nya. Manusia harus cinta kepada sesamanya, agar Tuhan cinta kepadanya. ${ }^{13}$

\footnotetext{
${ }^{11}$ Yaya Suryana dan A. Rusdiana, Op. Cit., h. 235-241

${ }^{12}$ Indra Djati Sidi, Menuju Masyarakat Belajar; Menggagas Paradigma Baru Pendidikan, (Jakarta: Logos, 2001), h. xix-xx

${ }^{13}$ Ibid., h. xviii
}

\section{Tema Persaudaraan}

Tema persaudaraan ini intinya hendaklah kita tidak mudah merendahkan golongan yang lain, tidak saling menghina, saling menggejek, banyak berprasangka, suka mencari-cari kesalahan orang lain, dan suka membicarakan orang lain yang tidak ada di depan kita. ${ }^{14}$

\section{Tema Persamaan}

Tema ini maksudnya yaitu semua manusia, tanpa memandang jenis kelamin, kebangsaan ataupun kesukuan, adalah sama dalam harkat dan martabat.

\section{Tema Baik Sangka}

Tema baik sangka yaitu tema yang menghendaki sikap penuh baik sangka kepada sesama manusia karena secara fitrah atau kejadian asal yang suci, manusia adalah baik. Manusia pada hakikat aslinya berkecenderungan kepada kebenaran dan kebaikan. ${ }^{15}$

\section{Reorientasi Pendidikan Berbasis Multikultural}

Ada beberapa reorientasi pendidikan berbasis multikultural yaitu: ${ }^{16}$

\section{Revitalisasi Kurikulum}

Pendidikan berbasis multikultural dalam kurikulum menjadi sangat strategis dan penting dengan pelaksanaan otonomi daerah dan desentralisasi pendidikan. Ragam kultur akan memberikan peluang bagi keutuhan dalam membentuk budaya bangsa. Membina ke-bhinekaan budaya berarti memahami dan menghargai perbedaan yang ada di warga masyarakat bangsa ini. Ke-bhineka-an budaya harus menjadi bagain integral proses pendidikan pada semua jenis, jenjang, dan jalur pendidikan.

\footnotetext{
${ }^{14}$ Ibid., h. xix

${ }^{15}$ Ibid., h. xx

${ }^{16}$ Yaya Suryana dan A. Rusdiana, Op.Cit., hh. 230-233
} 
Fokus pembahasan pendidikan multikultural, yaitu

a. Etnisitas, yaitu penelaahan terhadap berbagai kelompok etnis/budaya, keunikan masing-masing etnik serta konstribusnya terhadap kebudayaan nasional.

b. Mempelajari dampak dari ketidakadilan.

c. Proses pembelajaran. Implikasi dari pendidikan multikultural ini mencakup hasil serta proses instruksionaln, tujuan pembelajaran, materi pembelajaran, proses pembelajaran, dan evaluasi.

d. Kurikulum yang bersifat akomodatif dan komprehensif.

Upaya revitalisasi kurikulum dalam mengakomodasi multikultural hendaknya mengidentifikasi hal-hal berikut.

a. Faktor sosial budaya yang dapat menjadikan perbedaan individual peserta didik sebagai faktorfaktor yang konstruktif.

b. Mengidentifikasi nilai-nilai yang sepatutnya diajarkan secara eksplisit atau implisit.

\section{Penerapan Empat Pilar Proses Pembelajaran}

Ada empat pilar proses pembelajaran, yaitu ${ }^{17}$

a. Learning to Know

Penerapan learning to know dapat diterapkan di berbagai tingkat pendidikan sejak pendidikan dasar. Melalui penerapan paradigma ini peserta didik akan memahami dan menghayati suatu pengetahuan yang diperoleh dari fenomena yang terdapat dalam lingkungannya.

b. Learning to Do

Penerapan pilar ini merupakan upaya agar peserta didik menghayati proses belajar dengan melakkan sesuaty yang bermakna, suatu pembelajaran yang dikenal dengan active learning.

\section{c. Learning to Be}

Penerapan pilar ini merupakan prinsip pendidikan yang dirancang bagi terjadinya proses pembelajaran yang memungkinkan lahirnya manusia terdidik mandiri. Kemandirian akan tumbuh dari sikap percaya diri dan sikap percaya diri akan lahir dari pemahaman dan pengenalan dirinya secara tepat.

\section{d. Learning to Live Together}

Penerapan pilar ini dipandang penting karena pada era globalisasi yang sarat dengan muatan teknologi dan perdagangan bebas, dimensi kemanusiaan yang dijunjung tinggi oleh setiap agama sering terlupakan karena tekanannya pada pertambahan nilai secara kebendaan. Proses pembelajaran memungkinkan peserta didik menghayati hubungan antara manusia secara intensif dan terus-menerus sangatlah penting.

\section{Integrasi Empat Pilar dengan Pendidikan yang Berbasis Multikultural}

Budaya damai akan terwujud berdasarkan multukultural bangsa Indonesia dengan cara mengintegrasikan pendidikan berbasis multikultural.

\section{Strategi Pengembangan Pendidikan Multikultural}

Strategi yang dapat dikembangkan untuk tercapainya tujuan pendidikan nasional berbasis multikultural, antara lain sebagai berikut. ${ }^{18}$

1. Pengembangan Kurikulum

Pengembangan kurikulum dapat dilakukan dengan pembaharuan kurikulum yang mengutamakan materi yang esensial dan sistem evaluasi yang relevan dengan tujuan pendidikan nasional.

2. Peningkatan kualitas Profesional Tenaga Kependidikan 
Peningkatan dapat dilakukan dengan dengan penyempurnaan sistem pendidikan prajabatan dan dalam jabatan guru, serta pembinaan guru untuk meningkatkan kewibawaan guru dan tenaga pendidikan lainnya.

3. Pengembangan Sistem Pengelolaan Pendidikan

Pengembangan yang dapat dilakukan yaitu dengan mengembangkan sistem pengelolaan pendidikan dengan menegakkan sekolah/lembaga pendidikan sebagai pusat pembudayaan nilai-nilai yang sesuai dengan tuntutan masyarakat maju yang berdasarkan Pancasial.

4. Pengembangan Sistem Pendidikan Tinggi Sistem pendidikan tinggi perlu dikembangkan dengan melaksanakan Tri Dharma Perguruan Tinggi sehingga dapat menjadi agen pembangunan masyarakat.

5. Penyamaan Persepsi Masyarakat

Orang tua, tokoh masyarakat, dan pemimpin formal perlu menyamakan persepsi tentang perlunya memberikan dukungan bagi terlaksananya fungsi dan tercapainya tujuan pendidikan nasional.

Pengembangan pendidikan multikultural, menurut Lubis, dapat dilakukan dengan tiga hal, yaitu $^{19}$

a. Menanamkan pengenalan (pemahaman) dan penghargaan terhadap keberagaman (kultur atau budaya, etnis, ras, agama, pandangan hidup dan seterusnya). Pengenalan dan penghargaan atas keberagaman ini dapat dilakukan di ruang-ruang persekolahan atau di luar ruang-ruang kelas atau baik melaui jalur pendidikan formal, informal maupun nonformal.

${ }^{19}$ Akhyar Yusuf Lubis, Op. Cit., h. 191-192 b. Menghindari pandangan-pandangan yang menganggap bahwa kelompok yang satu lebih unggul dari kelompok yang lain. Ini berarti bahwa perlu dikembangkan dalam dunia pendidikan adalah sikap dan pandangan egalitarian atau nilai-nilai kemanusiaan.

c. Menumbuhkan dan membiasakan sikap dialogis. Terjalinnya dialog dapat menghindari adanya konflik. Dialog amat dibutuhkan di tengah-tengah kehidupan masyarakat yang plural. Dialog merupakan jembatan bagi interaksi di antara kelompok-kelompok yang berbeda. Sikap dialog ini mesti dikembangkan sedini mungkin di dunia pendidikan.

\section{Kesimpulan}

Pendidikan multikultural merupakan pemahaman tentang beraneka ragam kebudayaan, ide, gerakan pembaharuan pendidikan dan proses pendidikan yang tujuan utamanya adalah untuk mengubah struktur lembaga pendidikan dan mengembangkan (mengekplorasi) perbedaan sebagai bentuk keniscayaan. Tema pendidikan multikultural di Indonesia meliputi ketuhanan, kemanusiaan, persatuan dan kesatuan, kerakyatan, keadilan, silaturrahmi, persaudaraan, persamaan, dan baik sangka.

Strategi pengembangan pendidikan multikultural yang dapat dilakukan, yaitu pengembangan kurikulum, peningkatan kualitas profesional tenaga kependidikan, pengembangan sistem pengelolaan pendidikan, pengembangan sistem pendidikan tinggi, penyamaan persepsi masyarakat, menanamkan pengenalan (pemahaman) dan penghargaan terhadap keberagaman (kultur atau budaya, etnis, ras, agama, pandangan hidup dan seterusnya), menghindari pandangan-pandangan yang menganggap bahwa kelompok yang satu lebih unggul dari kelompok yang lain, dan menumbuhkan dan membiasakan sikap dialogis. 


\section{Daftar Pustaka}

Akhyar Yusuf Lubis, Pemikiran Kritis Kontemporer dari Teori Kritis, Cultural Studies, Feminisme, Postkolonial hingga Multikulturalisme, Jakarta: Raja Grafindo Persada, 2015.

James A. Bank dan Cherry A.McGee(ed), Handbook of Research on Multicultural Education, San Francisco: Jessey-Bass, 2001.

Junaedi, dkk., Strategi Pembelajaran, Surabaya: LAPIS-PGMI, 2008.

Jurnal Al-Ta'dib, Vol. 7 No. 2 Juli-Desember 2014, http://ejournal.iainkendari.ac.id/index.php/altadib/article/view/321
Jurnal Edueksos, Vol III No. 2, Juli-Desember 2104, https://www.syekhnurjati.ac.id/jurnal/index.php/ edueksos/article/view/354

M. Sukardjo dan Ukim Komarudin, Landasan Pendidikan: Konsep dan Aplikasinya, Jakarta: Rajawali Pers, 2009.

Yaya Suryana dan H.A. Rusdiana, Pendidikan Multikultural: Suatu Upaya Penguatan Jati Diri Bangsa, Konsep, Prinsip, Implementasi, Bandung: Pustaka Setia, 2015. 